\title{
Degree of having Teachers of Mathematics for the Secondary Stage of Evaluating Competences at Schools of Mafraq Governorate / Jordan from Their Point of View
}

\author{
Awad Mufleh Shehab Alkhazam ${ }^{1}$ \\ ${ }^{1}$ Faculty of Education Science, The World Islamic Sciences and Education University, Jordan \\ Correspondence: Awad Mufleh Shehab Alkhazam. E-mail: awad_kaldy@yahoo.com
}

Received: February 13, 2018

Accepted: March 3, $2018 \quad$ Online Published: March 20, 2018

doi:10.5539/ass.v14n4p123

URL: https://doi.org/10.5539/ass.v14n4p123

\begin{abstract}
This study aimed at revealing and investigating the degree which teachers of mathematics at the secondary stage, the calendar competences at the schools of Mafraq governorate in Jordan from their point of view (gender variables, educational qualifications and teaching experience). To achieve the objective of this study, the researcher prepared a questionnaire including two areas of the competences of the teachers' personal and cognitive competences, consisting of (30) items divided into domains (15) for each. The sample consisted of (62) female and male teachers who were teaching at secondary stage. To extract the results, the researcher used the analysis of the three way ANOVA and multivariate variance in line with means and standard deviations. The results showed that the degree of having secondary teachers of mathematics at schools of Mafraq governorate for evaluation competences of students' learning was medium, while the total mean was of $(3,37)$. The results also showed that there were no statistically significant differences at the level of $(\alpha \leq 0.05)$ to the extent of having secondary teachers of mathematics at schools of Mafraq governorate for evaluation competences of learning from their point of view due to gender variable. Whereas, the results showed that there were statistically significant differences at the level of $(\alpha \leq 0.05)$ of the degree of having evaluation competences in experience and qualification variables in favor of experience (more than 5 years) and for the scientific qualification which is higher than the bachelor degree.
\end{abstract}

Keywords: evaluation competences, teachers of mathematics, secondary stage

\section{Introduction}

\subsection{Theoretical Background of Study}

The evaluation in the educational process is an integral part of the educational learning process and a basic element of its pillars. It is the wave and guide for the entire educational process. The educational process is not valid and achieves its goals without it. The evaluation in the educational process is of great importance through the important role it plays. It is possible to determine the extent to which the student achieves the goals he aims at, monitoring his achievement and making decisions to prepare for the reform and development of education. Othman (2011) states that evaluation leads to multiple functions in the educational process, including the self-assessment of the teacher through which he/she is assisted to manage the effectiveness of teaching and help students achieve their goals, which prompts the teacher to develop his methods and improve the methods of education and improve the performance.

In the course of analyzing the data of such study, Popham (2005) sees that there are many information about the calendar that teachers need to invent classroom assessment tools, interpret the results of these tools to their parents, monitor the progress of student learning, provide instant feedback to them first hand, and the ability to diagnose students' weaknesses and ability on how evaluate tests.

Another study by AlTanawi (2013) believes that the evaluation is the guide that guides the educational system with its various components in the right direction through the feedback it provides. It begins by collecting information and data related to a particular subject and ends with a decision on this subject. In teaching on the one hand and overcoming the difficulties facing learners on the other. Also, Mustafa (2010) indicates that the qualities of an efficient and effective teacher has to have personal and cognitive calibrations. Personal competences are represented in: justice in evaluation and impartiality, focus on self-assessment and make it part 
of the classroom assessment, professional development, propose solutions appropriate to them, keep abreast of developments and changes in the field of specialization, the ability to adapt to them, provide feedback to students in a friendly manner, and involve students when selecting tools and criteria for agreeable evaluation.

According to cognitive evaluation competences may include: the use of evaluation strategies and tools, to recognize the philosophy and objectives of education, to clearly define the goal of the evaluation, to the diversity of assessment strategies and tools, to collect, analyze and interpret data, to utilize the results of the evaluation and its use to address weaknesses and enrich the strengths and knowledge. The content of the curriculum and the textbooks prescribed for the subject of study, its objectives and the analysis of its content. It has the ability to recognize its rights, duties and responsibilities, to recognize the methods of evaluating the results of its students' learning, the ability to build and analyze tests, old feedback to students, to prepare appropriate material for the measurement of educational tools, applying evaluation skills in different positions descriptive, and has the ability to employ technology in the evaluation process.

Competence as an educational concept, has many definitions to the extent that it is difficult to define a unified definition. However, despite this multiplicity, it leads to the clarification of its meaning more especially since each definition looks at the adequacy from a certain angle according to the nature of the research. A certain level of knowledge, skills, values and attitudes is sufficient to be able to achieve the orthodontic performance of the learning process, which is reflected in the behavior of students.

Terminologically, competency refers to the highest level of knowledge, skills, values and attitudes that a teacher can perform in his/ her educational tasks with the highest level of proficiency that can be accessed, observable and measured, and leads to the growth of students' behavior, namely, maximum competence and control to the mechanical degree of skill, ability or adequacy of competences (Ghareeb, 2006).

Using data for analyzing the degree of evaluation adopted by teachers of mathematics, another study states that the competences of the evaluation are one of the ones that the teacher must have. The teacher requires diversity in the use of the methods and tools of the assessment, the formulation of different test subjects in light of educational goals, the detection of strengths of students, the ability to analyze the results of tests and observations and tabulation of data in a form that facilitates the extraction of results and interpretation to benefit from them, contribute to the evaluation of the educational process in all its various components, and writing school reports thoroughly Ta'imah (2006).

In addition, Odeh (2010) sees that the teacher's evaluation process by holding examinations, oral questions, or observations to determine success in achieving the objectives of the curriculum is often not inclusive of all aspects of growth and is not concerned with diagnosis and treatment, but rather with the extent to which the goals are achieved; this may be closer to the measurement than to evaluation. The evaluation of student learning is one of the areas of the national standards for the development of teachers professionally in Jordan, where the teacher has in this area the skills of planning the classroom evaluation, building appropriate tools, modifying the plans of teaching based on feedback, and has the knowledge in the use of evaluation strategies in the process of learning and education. Therefore this aspect includes eight criteria:

1. Understands the relationships between learning products, teaching and assessment of student learning;

2. Selects or designs appropriate and varied tools to assess and advance students' learning according to intended learning outcomes and uses them effectively;

3. keeps accurate records of students' conditions and progress according to intended learning outcomes, including tools and means of information and communication technology;

4. Communicates with the school administration and the educational district about the student's learning and progress;

5 - Involves students in assessing their learning and progress in it;

6. Analyzes students' performance and provides instant feedback to them through their learning and progress;

7. Designs appropriate learning activities to promote student learning in light of the results of their learning assessment and progress; and

8. Communicates with his fellow teachers outside the school to develop himself professionally (Ministry of Education, Jordan, 2006).

On the other hand, (Al Adwan \& Al Hawamdeh, 2015) mention that teacher of mathematics has to have many competences in the field of evaluation to be able to teach mathematics: 
- To be committed to justice in the assessment of students' learning;

- Implements evaluation at different stages (preliminary (pre - constructive - final);

- Evaluates the cognitive, skill and emotional facets of students in fairly;

- Evaluates students' work during collaborative learning;

- Evaluates students' work during peer learning;

- Uses realistic alternative assessment methods;

- Provide students with assessment criteria at the beginning of the study;

- Amends the solutions - though the final solution;

- Uses multiple axes to evaluate students' work;

- Amends the basic skills in the lesson;

- Encourages students to do their own work (self-assessment);

- Combines evaluation and orientation;

- Uses the book of exercises effectively;

- Organizes the results of analysis of evaluation data in the form of tables and graphs showing the level of achievement and progress of each student;

- Uses evaluation results to modify learning strategies;

- Uses evaluation results to provide feedback to students;

- Uses results of the evaluation to design alternative assessment tools and methods;

- Involves the family in the evaluation of their studying children;

- Varies in methods of evaluation whether they are written or oral; and

- Amends thinking skills.

\subsection{Problem and Questions of Study}

There have been numerous studies on the educational competences of the teacher, whether those interested in the educational qualifications or standards necessary for those who wish to practice the teaching profession in general, or those of the teachers of individual materials, and as a result of these researches and studies, most of which aimed at high lighting what educational competences or standards have an active role in both process education and learning, reflected positively on the achievement of student learning, and emerged lists of various educational competences and standards that the teacher must apply and adhere to when he takes over the work.

Regarding to cognitive developments in the role of the teacher in the light of the challenges of the twenty-first century and the recent trends in teacher training according to the quality system, and the importance of the teacher's evaluation criteria in raising and improving the level of student performance, there was a need to develop and develop training programs and plans for teacher preparation. So, the Ministry of Education implemented a series of training programs that serve and raise the competences of the teacher professionally, especially with the development of textbooks based on the teaching strategies and strengthen a new curriculum covering all teachers (Ministry of Education, 2006).

Upon the researcher's knowledge, there are no specialized studies dealing with the competences of the calendar of the teacher of mathematics and the degree of ownership of it yet. Therefore, this study was an attempt to provide a window on evaluation competences and to reveal the degree of having teachers of mathematics of secondary stage, the evaluation competences at the schools of Mafraq in Jordan from their points of view. Such competences and practice are undoubtedly have a great benefit to the educational process of learning, and lead to take appropriate decisions to help achieve the desired educational goals.

\subsection{This Study Aimed at Answering the Following Questions}

1- What is the degree to which the teachers of mathematics for the secondary stage having evaluation competences at the schools of Mafraq Governorate in Jordan from their point of view? and

2- Are there differences of statistical significance $(\alpha \leq 0.05)$ in the mean of having teachers of mathematics for the secondary stage of evaluation competences at the schools of Mafraq Governorate in Jordan from their point of view due to the variables: gender, educational qualification, teaching experience? 


\subsection{Hypotheses of Study}

1- There were no statistically significant differences at $(\alpha \leq 0.05)$ in the mean responses of the sample of study on the degree of ownership calendar competences at schools of Mafraq Governorate / Jordan from their point of view due to gender.

2- There were no statistically significant differences at $(\alpha \leq 0.05)$ in the mean responses of the sample of study on the degree of ownership, the evaluation competences at schools of Mafraq Governorate /Jordan, from their point of view due to the qualifications.

3- There are no statistically significant differences $(\alpha \leq 0.05)$ in the mean responses of the sample of study on the degree of ownership of evaluation competences at schools of Mafraq Governorate in Jordan from their point of view due to teaching experience.

\subsection{Importance of Study}

The importance of this study stems from the fact that it contributes to addressing some problems of practical education and the professional growth process of teachers of mathematics, especially in relation with the process of evaluating students' learning. It also attempts to determine the degree to which secondary school teachers of mathematics have the ability to teach students in their teaching. Helps officials in the Jordanian Ministry of Education raise the competences of teachers of mathematics and enable them to build training programs based on these competences. The researcher also expects that this study will contribute in developing a list of the evaluations that the teachers of mathematics do not have, as well as to enrich the field of educational research in the competences of the evaluation for the development of teachers professionally, especially with regard to the process of evaluation in terms of teaching students.

\subsection{Terminology of Study}

- Evaluation competences: (AlSaqrat, 2006) defined the competence as: "the ability to perform a certain behavior linked to the tasks of teaching in the teaching consists of tasks, knowledge and trends related to teaching, be measurable, assessment and lead to a degree of perfection to achieve the desired goals". In this regard, the researcher defines competence of evaluation as a procedural definition: the best level that can be reached by the teacher of mathematics at the secondary stage in terms of abilities, skills and capabilities in the domain of evaluating students' learning of personal and cognitive competences, which have been identified in items of the study tool.

-The degree to which teachers have the competences of evaluation: the abilities, skills and potentials of teachers of mathematics in the secondary stage in the domain of assessment at students' learning. It is measured by the degree that the teacher herself/himself appreciates by the degree he/she receives mathematics by answering sections of the study instrument.

- Teachers of mathematics: are all teachers who hold a scientific qualification from the bachelor level in mathematics, higher scientifically or educationally, and work in the domain of teaching at the secondary stage, at public schools of the Directorate of Education, the Department of Qasbat -Al Mafraq for the first semester of the academic year 2017 / 2018.

- The Secondary stage: is the stage of education that follows the compulsory basic stage after the tenth grade, extending to two years after they are: the first secondary and secondary streams (literary and scientific) in the Jordanian educational system.

\subsection{Study Limitations}

1. This study was limited to the competences of evaluation in each of the two areas: (personal evaluation competences) and (cognitive assessment competences).

2. This study was limited to secondary teachers of mathematics who studied mathematics in the scientific and literary streams at public schools affiliated to the Directorate of Education of the faculty of Qasbat Al Mafraq during the first semester of the academic year 2017/2018.

3. The degree to which teachers have the competences (personal and cognitive) from their point of view based on their response to the sections of study tool prepared for this purpose.

\subsection{Previous Studies}

In the context of testing the educational competences, AlRababah (2016) conducted a study aimed at building a list of the educational competences necessary for teachers of Arabic language for non-Arabic speakers and indicated to the extent of their practice according to the variables of qualification, gender and years of experience. 
It has been done within a sample consisted of (24) female and male teachers, and concluded to the construction of a list of educational competences needed for teachers of Arabic language for the non-Arabic speakers. whose Arabic language for non-Arabic speakers had three areas of educational competences were very high, and other three areas were high while one domain was at medium degree and one more was low. The results showed that there were no statistically significant differences in the degree of practicing Arabic language teachers for the other educational competences due to the variables of gender, academic qualifications and specialization. However, there were statistically significant differences in the degree of practicing Arabic language teachers for non-native speakers of educational qualifications due to years of teaching experience and in favor of teachers who had experience more than (6) years.

Another study was conducted by AlOmari (2010) aimed at determining the competences necessary to teach the curriculum of mathematics developed, to determine the degree of availability of teachers according to four variables (scientific qualification, years of service, training courses, number of students in the classroom). Results showed the availability of competences of planning, implementation and evaluation were medium, while results did not show significant statistical differences attributed to the scientific talent, as well as showed differences in statistical significant due for each of the years of service, training sessions and the number of students in the classroom in degree of availability of those competences.

In a study conducted by AlZahrani (2009), it aims at building a list of the professional standards for the teachers of mathematics performance in the secondary stage in Saudi Arabia and to determine the availability of these criteria. The sample consisted of (45) teachers of secondary school mathematics in Madinah. Results showed the availability of professional standards in overall performance, in the domain of planning, instructional design, and effective teaching by teachers of mathematics during the period. Results showed no significant statistical differences between the means of the total teaching performance of the groups of secondary school teachers of mathematics in light of the professional standards due to the difference in years of service, weekly share of periods, crowded classrooms of students.

Moreover, AlSuggaf (2008) conducted a study aimed at determining the educational competences necessary for teachers of mathematics at the secondary stage and the degree of practicing them according to gender, qualification and experience variables. The sample consisted of (30) female and male teachers. Results showed that the number of competences exercised by teachers (55) is sufficient for planning, implementation and evaluation, and that the degree of practicing them was medium. Results also showed no significant differences between the teachers due to the type of teacher, his qualifications and his experience.

In addition, Abaid (2008) conducted a study aimed at estimating the effectiveness of the training courses held by the Ministry of Education for teachers during service in the domain of measurement and evaluation on the adequacy of teachers of mathematics in the construction of the school achievement tests for the basic stage in the Directorate of Education of first Amman. The study consisted of (80) teachers in the domain of measurement and evaluation on the adequacy of teachers of mathematics in the construction of the school achievement tests for the basic stage in the first Amman Education Directorate. The study tool was a test of the cognitive competence of the teachers in the criteria of building the scholastic achievement test in light of general theoretical knowledge. Results showed that the training courses held by the Ministry of Education for teachers during service in the domain of measurement and evaluation affected the adequacy of teachers of mathematics in the construction of school achievement tests for the basic stage to a medium degree. Results also showed no statistically significant differences between the degree of knowledge of teachers of mathematics and the criteria for building school achievement tests due to gender.

In a study of Varma (2007), it aimed at improving the quality of primary education by noting the professional competences teachers of comprehensive education. The results indicated that teachers should be trained to use teaching methods based on students' needs and to employ available infrastructure. Additionally, to subject new teachers in educational institutions service to training programs during service, and provide them with skills, strategies and competences which help them provide learners with skills to enable them satisfy their needs in their own way.

In a course of analyzing information about mathematics teaching, AlRashidi (2007) aimed in the study at determining the degree to which teachers of mathematics have the teaching skills and their relation to the achievement of their students at primary school in Kuwait, the sample consisted of 28 teachers and 566 students at fourth grade. A questionnaire to determine the degree to which teachers of mathematics have access to teaching skills and a student achievement test. The results showed that the degree of having teachers of mathematics for the primary level of teaching skills was medium, where the most skills available to teachers of 
mathematics to implement the lesson, followed by the field of planning for the lesson, and the field of evaluation ranked third. The results also showed that the relationship between student achievement and the degree of teacher having teaching skills was positive.

AlThubaiti (2005) conducted a study aimed at knowing the availability and practice of educational competences in the preparation, correction and analysis of the test among the secondary school teachers of mathematics in Taif educational city in light of some variables such as educational qualification, years of experience and measurement courses. The sample consisted of (129) teachers. The researcher used two tools of study: test and questionnaire to reach the goals of study. So, the results showed a decrease in the availability and practice of educational competences in the preparation, correction and analysis of the test among secondary school teachers of mathematics in Taif. Results also showed statistically significant differences in the availability of educational competences, The test is due to the educational qualification, years of service and number of measurement courses.

Additionally, AlMezian and Gharrab (2005) conducted a study aimed at determining the basic competences of kindergarten teachers in the Gaza governorates from the point of view of kindergarten female principals. The sample of study consisted of (120) principals. Results showed that the domain of professional competence ranked the highest degree of interest among the principals, the physical competences ranked second, then the emotional competences third, and cognitive competences ranked last, where all competences ranked high percentage.

Qoqazeh (2003) conducted a study to determine the availability and practice of educational technical competences among secondary school teachers of mathematics in Jerash. The study sample consisted of (62) teachers, while the study tool consisted of (69). Results showed that (34) high educational efficiency (33) with medium grade, and (2) very low. Results showed that the teachers of mathematics at the secondary level in Jerash governorate of (44) were high competence (23) were medium and (2) were low, as well as differences in availability and practice of technical teaching competences among teachers of mathematics at the secondary level in Jerash Governorate due to the impact of service and qualification.

Also, a study conducted by AlZahrani (2002) aimed at identifying the degree of having of teachers of mathematics at the primary stage of knowledge competences for the preparation of achievement tests, the sample consisted of (268) teachers who teach mathematics at the primary stage in Madinah Al Munawwarah, while the researcher used questionnaire as a tool. The teachers of mathematics at the primary stage of cognitive competences for the preparation of the achievement tests in general were low, and the results showed that there were statistically significant differences between the responses of teachers of mathematics at the primary stage in the degree of having knowledge competences. The results of the tests were statistically significant differences between the responses of teachers of mathematics at the primary stage. In the degree to which they have the cognitive skills to prepare the achievement tests was attributed to the educational service in the domain of teaching.

\subsection{Commenting on Previous Studies}

Through the researcher's review of previous studies, it is shown that there is increasing interest by educational researchers in determining the competences necessary for teachers, and to know their level of competence and the degree of their practice of adequacy. The main objective of most of these studies is to determine the list of educational competences (teaching) necessary for the teacher. While most of the previous studies overlooked the teacher's competences as a separate subject because of its importance to the other competences of the teacher, where the competences of the evaluation head of the rest of the other competences of the teacher, and merged with the teaching competences of the teacher. In the course of analyzing the data, this study takes into consideration the detailed competences, which are unique in it. Combining the analysis of data services with several most of the previous studies, this study differs in their geographic locations, their importance, their objectives, their samples, and the statistical methods used to analyze their information. It is consistent with them in the most important component that contributes in the development of performance, and competences of the teacher and raise the level of education.

\section{Methods and Procedures}

The researcher used descriptive method in the survey.

\subsection{Community of Study}

At the main study site, the researcher selected the community that who consists of all female and male teachers of mathematics in the secondary stage of public schools at the three directorates of education in Al-Mafraq 
Governorate (Directorate of Education of Qasbat Al-Mafraq, Directorate of Education of in the Northern Badia, Directorate of Education of in the East Badia) province, (63) male teachers and (61) female ones are respectively distributed at (78) public schools and three directorates of education by approximate 2: 1: 1 .

\subsection{Sample of Study}

Members of study are (62) teachers and teachers of mathematics at schools of the Directorate of Education of Major General Qasbat, Al Mafraq for the first semester of the academic year 2017/2018, -that is, (50\%) of the study population. They were selected at random cluster sampling method, where the directorate was the selection unit, and Table 1 illustrates the distribution of the sample of study participants according to variables.

\begin{tabular}{|c|c|c|c|}
\hline \multicolumn{2}{|c|}{ Variable } & Size of sample & percentage \\
\hline \multirow{2}{*}{ Gender } & Male & 31 & $50 \%$ \\
\hline & Female & 31 & $50 \%$ \\
\hline \multirow{2}{*}{ Qualification } & Bachelor & 38 & $61 \%$ \\
\hline & Above Bachelor & 24 & $39 \%$ \\
\hline \multirow{2}{*}{ Experience by years } & Below 5 & 27 & $44 \%$ \\
\hline & More than 5 & 35 & $56 \%$ \\
\hline \multicolumn{2}{|c|}{ Total } & 62 & $100 \%$ \\
\hline
\end{tabular}

\subsection{Tool of Study}

To achieve the objective of this study, the researcher constructed a questionnaire to identify the degree of having teachers of mathematics for the secondary stage of the evaluation competences, derived from the educational literature related to the subject of the study and the previous studies related to teaching competences. The initially items(35) were divided into the domains of study. The first domain: the personal evaluation competences and was assigned into (17) items, and the second domain: cognitive evaluation competences and (18) items were assigned to. Teachers of mathematics were asked to answer all items of the questionnaire, to determine the degree of having skills of evaluation from their point of view, so that the teacher determines the degree of having among the five-degree grades according to the following five- degree Likert scale for each combined degree: (5) degrees for very high, (4) for high, (3) for medium, (2) for low and (1) for very low. The researcher adopted the following steps when constructing the questionnaire:

- reviewing theoretical literature, research and previous studies related to the study and its variables.

- reviewing the publications issued by the Jordanian Ministry of Education, especially regarding the evaluation strategies and its tools.

- designing the content of the questionnaire in the light of theoretical literature, previous studies, brochures and booklets of the Ministry of Education concerning the competences of teachers, especially the evaluation.

\subsection{Validity of Tool}

To verify the validity of the tool, the researcher presented the questionnaire to a committee composed of (6) arbitrators -professors in Jordanian universities, (4) educational supervisors specialized in mathematics at directorates of education and (10) teachers experienced and functionally excellent in mathematics. They were all asked to express their opinions on the questionnaire in terms of: the clarity of the items, the integrity of language, the relevance of the items to the domain in which they were included, and were allowed to amend, delete or add. The necessary amendments were made in light of observations made by the majority of the members of the Committee. For instance, two items of the questionnaire relating to the first domain and other three items of the second domain were excluded, as well as some items were paraphrased. Therefore, the questionnaire in the final form included (30) items; (15) for each domain.

\subsection{Reliability of Test}

To verify the reliability coefficient of the study tool, by means of testing and retesting, the study tool (questionnaire) was applied to other sample of the study community from non- sample of study consisted of (30) female and male teachers. By using Cronbach-alpha, the reliability coefficient of the tool was obtained at (0.92) as a whole to the extent that the secondary teachers of mathematics at schools of Al-Mafraq governorate had the evaluation competences for teach from their point of view as shown in Table 2. 


\begin{tabular}{ccc}
\hline No & Domain & Reliability value \\
\hline 1 & Personal evaluation competences & .91 \\
2 & Cognitive evaluation competences & .88 \\
& Having evaluation competences & .92 \\
\hline
\end{tabular}

\subsection{Variables of Study}

1. Independent variables are:

- Gender has two levels: males and females.

- Experience has two levels: 5 years and below, and more than 5 years.

- Qualification has two levels: Bachelor, above Bachelor.

2. The dependent variable: is the variable that represents the degree to which teachers of mathematics in the secondary stage having evaluation competences from their point of view through their answers to items of the prepared questionnaire.

\subsection{Procedures of Study}

After the researcher had built the tool of study and verified its validity and reliability, it had to implement the study according to the following steps: The sample of study was determined by the random simple stratified method consisted of female and male secondary teachers of mathematics at schools of the North West Badia Directorate. They were requested to fill the questionnaire, data were then introduced for appropriate analysis using the SPSS program, and scheduling of results.

\subsection{Statistical Processes}

To answer questions of study, the researcher used the statistical package program (SPSS) as means and standard deviations of the study domains for each of sections of the study instrument as well as for each of its domains, and for the tool as a whole, as well as the use of three way ANOVA and multivariate analysis to detect the effect of the three demographic variables. To determine the degree of application, the standard was adopted according to the following equation, which determines the length of the category, which was at (1.33).

Length of category $=($ maximum of scale - the minimum of scale $) \div($ Number of categories $)$

$$
\text { Length of category }=(5-1) \div 3=1.33
$$

Thus, the categories are as follows:

(From 1 to 2.33): low

(From 2.34 to 3.67): medium

(From 3.68 to 5): high

\section{Results of Study and Discussion and Recommendations}

Results related to the first question: What is the degree of evaluation competences of teachers of mathematics of secondary stage at schools of Mafraq governorate from their point of view?

To answer the first question, the means and standard deviations were extracted for each item, domain and its tool as a whole, which show the degree to which the secondary teachers of mathematics at schools of Al-Mafraq governorate have the evaluation competences.

Table 3 shows means, standard deviations, degree of having evaluation, and rank of instrument clauses are in descending order.

\begin{tabular}{cccccc}
\hline & \multicolumn{2}{c}{ First: Personal evaluation competence } \\
\hline $\begin{array}{c}\text { Number of } \\
\begin{array}{c}\text { competence in } \\
\text { questionnaire }\end{array}\end{array}$ & Rank & Items & Mean & $\begin{array}{c}\text { Std. } \\
\text { D }\end{array}$ & $\begin{array}{c}\text { Degree } \\
\text { 2 }\end{array}$ \\
\hline 2 & 1 & Having fair and impartiality in evaluation. & 4.85 & .63 & High \\
4 & 2 & Helping students focus on self-assessment. & 4.76 & .69 & High \\
1 & 3 & $\begin{array}{c}\text { Developing students professionally in things related to } \\
\text { measurement and evaluation in the teaching process. }\end{array}$ & 4.68 & .73 & High \\
\hline
\end{tabular}




\begin{tabular}{|c|c|c|c|c|c|}
\hline 3 & 4 & Continuity in the evaluation process in classroom situations & 4.52 & .75 & High \\
\hline 7 & 5 & $\begin{array}{l}\text { Making the self-assessment an integral part of the classroom } \\
\text { evaluation. }\end{array}$ & 4.47 & 0.71 & High \\
\hline 5 & 6 & $\begin{array}{l}\text { Providing feedback to learners continuously, friendly and } \\
\text { directly after each evaluation. }\end{array}$ & 4.33 & .69 & High \\
\hline 8 & 7 & $\begin{array}{l}\text { Keeping pace with changes and developments in the field of } \\
\text { classroom evaluation. }\end{array}$ & 3.99 & .75 & High \\
\hline 10 & 8 & $\begin{array}{l}\text { Having ability to adapt to the changes and developments } \\
\text { associated with the field of assessment of students' learning in } \\
\text { the specialization filed. }\end{array}$ & 3.91 & .83 & High \\
\hline 14 & 9 & $\begin{array}{l}\text { Dealing with the evaluation problems encountered in teaching } \\
\text { process and proposing suitable solutions. }\end{array}$ & 3.61 & .77 & High \\
\hline 9 & 10 & $\begin{array}{l}\text { Observing the tools of the evaluation for all aspects of the } \\
\text { learner's personality }\end{array}$ & 3.50 & .70 & Medium \\
\hline 15 & 11 & Having ability to issue judgments related to the evaluation. & 3.44 & .81 & Medium \\
\hline 13 & 12 & Applying evaluation skills in different classroom situations. & 3.25 & .92 & Medium \\
\hline 11 & 13 & Having ability to employ technology in the evaluation. & 3.00 & .66 & Medium \\
\hline 6 & 14 & Involving students when choosing evaluation tools. & 2.32 & .58 & Low \\
\hline 12 & 15 & Involving students in the evaluation criteria agreeably. & 2.30 & .59 & Low \\
\hline \multicolumn{3}{|r|}{ Personal evaluation competence as a whole } & 3.80 & .62 & High \\
\hline \multicolumn{6}{|c|}{ Second: Cognitive evaluation competence } \\
\hline $\begin{array}{l}\text { Number of } \\
\text { competence in } \\
\text { questionnaire }\end{array}$ & Rank & Items & Mean & $\begin{array}{l}\text { Std. } \\
\text { D }\end{array}$ & Degree \\
\hline 18 & 16 & $\begin{array}{l}\text { Having knowledge of his rights, duties and responsibilities, } \\
\text { especially those related to the process of evaluation of the } \\
\text { teaching process. }\end{array}$ & 4.45 & .88 & High \\
\hline 29 & 17 & Setting the evaluation goal clearly. & 4.13 & .86 & High \\
\hline 20 & 18 & $\begin{array}{l}\text { Getting to know the importance of the calendar as an element } \\
\text { of the curriculum and the textbooks for the study. }\end{array}$ & 3.82 & .82 & High \\
\hline 22 & 19 & Diversify student learning assessment strategies. & 3.10 & .80 & Medium \\
\hline 23 & 20 & vary in student assessment tools. & 2.91 & .53 & Medium \\
\hline 17 & 21 & Linking evaluation to the goals and philosophy of education. & 2.86 & .67 & Medium \\
\hline 19 & 22 & $\begin{array}{l}\text { Collecting, classifying, tabulating, analyzing and interpreting } \\
\text { of data related to the evaluation. }\end{array}$ & 2.81 & .62 & Medium \\
\hline 27 & 23 & $\begin{array}{c}\text { Identifying the characteristics of the evaluation process and the } \\
\text { properties of each of its tools. }\end{array}$ & 2.77 & .87 & Medium \\
\hline 26 & 24 & $\begin{array}{l}\text { Linking the evaluation to the three target areas (cognitive, } \\
\text { psychological, emotional). }\end{array}$ & 2.76 & .95 & Medium \\
\hline 21 & 25 & $\begin{array}{c}\text { Having knowledge of non-testing tools and the ability to } \\
\text { construct }\end{array}$ & 2.71 & .91 & Medium \\
\hline 24 & 26 & Learning how to evaluate the outcomes of student learning. & 2.69 & .66 & Medium \\
\hline 16 & 27 & $\begin{array}{c}\text { Evaluating of students' learning according to specific rules and } \\
\text { criteria. }\end{array}$ & 2.42 & .51 & Medium \\
\hline 25 & 28 & $\begin{array}{l}\text { Analyzing of the content of the curriculum and textbooks for } \\
\text { the study he is studying for use in evaluating student learning. }\end{array}$ & 2.35 & .76 & Medium \\
\hline 30 & 29 & $\begin{array}{l}\text { Making achievement tests for students, taking into account the } \\
\text { good testing specifications. }\end{array}$ & 2.18 & .63 & Medium \\
\hline 28 & 30 & $\begin{array}{l}\text { Getting benefit from analyzing and using evaluation results to } \\
\text { address weaknesses and enrich students' strengths. }\end{array}$ & 1.62 & 1.01 & Medium \\
\hline \multicolumn{3}{|r|}{ Cognitive evaluation competence as a whole } & 2.97 & .91 & Medium \\
\hline \multicolumn{3}{|r|}{ Total degree for having two domains } & 3.37 & .86 & Medium \\
\hline
\end{tabular}


In the course of analyzing the data, Table 3 shows that the total means of the sample (for the domains of study and their items) regarding secondary teachers of mathematics having evaluation competences at schools of Mafraq governorate from their point of view was at (3.37). The results of this study were consistent with the results of (Al Rababah, 2016), (AlOmari, 2010), (AlSuggaf, 2008) and (AlRashidi, 2007) studies. While with the results of (Almezian \& Gharrab, 2005) and (AlZahrani, 2002) were not. This may be explained by the fact that these evaluation competences are at the core of work of mathematics of teachers at the secondary stage. It is one of the axioms and fundamentals that underlie the teaching process of the teachers in general and the teachers mathematics in particular. In addition, these competences are constantly monitored by gender principals, and supervisors there are some math teachers who take the evaluation skills seriously and others neglect them and have no motivation to own and practice them, is usually moderate. Moreover, Table 3 indicates to the highest means for the degree of having evaluation among secondary teachers of mathematics with mean of (3.80) and a standard deviation at (0.62).

The highest mean of this domain is item (2) in the questionnaire states: "having fair and impartiality" with mean of (4.85) and a standard deviation at (0.63) and was high. Then item (4) "students with self-assessment and concentration "with mean of (4.76) and a standard deviation at (0.69), and also was high for each.

To address this need, this result was consistent with the result of the study (Al Mezian \& Gharrab, 2005). Like other teachers with a high message, ethics and conscientious, the researcher attributes that to the teacher of mathematics at the secondary stage performs all students fairly and sincerely, and that students in this stage are able to possess the skill of self-evaluation, so the math teacher at this stage is to help, develop and enhance that enough.

In addition, the lowest competence of teachers of mathematics was in items (6) and (12) respectively, stated: "Involving students in the selection of evaluation tools." Whereas "Involving students in the evaluation criteria agreeably". On the lowest means in this field of (2.32), and (2.30) with a standard deviation at (0.58) and (0.59) respectively. The researcher sees that the students at this stage are unable to possess these skills since their competence requires skill, practice and intensive training, so the math teacher neglects it.

Then, domain of knowledge cognitive competences ranked second with mean of (2.97) and a standard deviation at $(0.91)$ was medium. While the highest mean of this domain was of $(4.45)$ and a standard deviation at $(0.88)$ for item (18) which states having knowledge of his rights, duties and responsibilities, especially those related to the process of evaluation of the teaching process. "

Also, item (29), which states: "clearly define the goal of the evaluation" with a mean of (4.13) and a standard deviation at (0.86) to a high. The result of this study is inconsistent with the result of Zahrani's study (2002). The researcher states that as long as the teacher has a supreme message to send and rights to have, he/she has duties to acknowledge, too. The community is viewed with optimism as a teacher, educator and a good example of the students. He has clear educational goals when evaluating his students' learning, seeks to modify their behavior and makes them happy for their academic excellence, enhances and shapes their balanced personality that will help them build their future since this effort will be recognized for him.

On the other hand, the two items (30) and (28), respectively, stipulate that: "making of collection tests that take into account the specifications of the good test." Utilizing the analysis and use of the evaluation results to address the weaknesses and enrich the strengths of students. This domain has low level means of (2.18) and (1.62) with a standard deviation at (0.63) and (1.01) respectively. The researcher therefore sees that most teachers, including teachers of mathematics, lack the experience and practical training to prepare their tests according to the specifications of the good test, and their concept of the evaluation process does not exceed the concepts of measurement and evaluation to perform their students and measure their academic achievement and make estimates, and the weakness of their ability to analyze the results of the test, because of the lack of experience and training them, and the lack of demand for their managers and supervisors so the lack of expertise and guidance to their teachers, too, so he finds them neglect those two previous cases.

The second question of study: Are there statistically significant differences at the level of $(\alpha \leq 0.05)$ in the degree of having secondary teachers of mathematics at schools of Al-Mafraq governorate for evaluation competences from their point of view due to the variables (gender, educational qualification, teaching experience)?

To answer it, the means and standard deviations of the demographic variables (gender, academic qualification, and teaching experience) were obtained. This shows the degree to which the secondary school teachers of mathematics in Mafraq governorate have the competence in their evaluation according to the demographic variables as illustrated in Table 4. 
Table 4 shows the degree to which the secondary school teachers of mathematics in Mafraq governorate have the evaluation competence according to the demographic variables

\begin{tabular}{|c|c|c|c|c|c|c|c|c|}
\hline \multicolumn{2}{|c|}{ Variable } & \multirow[t]{2}{*}{ No } & \multicolumn{2}{|c|}{$\begin{array}{l}\text { Personal evaluation } \\
\text { competences }\end{array}$} & \multicolumn{2}{|c|}{$\begin{array}{c}\text { Cognitive evaluation } \\
\text { competences }\end{array}$} & \multicolumn{2}{|c|}{$\begin{array}{c}\text { Evaluation competences } \\
\text { of tool as a whole }\end{array}$} \\
\hline & & & Mean & Std.D & Mean & Std.D & Mean & Std.D \\
\hline \multirow{2}{*}{ Gender } & Male & 31 & 3.80 & 0.55 & 2.99 & 0.58 & 3.40 & 0.52 \\
\hline & Female & 31 & 3.79 & 0.53 & 3.00 & 0.49 & 3.39 & 0.50 \\
\hline \multirow{2}{*}{ Qualification } & Bachelor & 38 & 2.66 & 0.60 & 2.59 & 0.64 & 2.63 & 0.67 \\
\hline & Above Bachelor & 24 & 3.98 & 0.52 & 3.70 & 0.44 & 3.84 & 0.46 \\
\hline Teaching & Below 5 & 27 & 3.70 & 0.53 & 2.46 & 0.70 & 2.58 & 0.66 \\
\hline experience by years & More than 5 & 35 & 4.64 & 0.58 & 3.98 & 0.43 & 4.33 & 0.51 \\
\hline
\end{tabular}

As shown in Table 4, there are some obvious differences between demographic variables (educational qualification, teaching experience) and gender. To detect these differences, the ANOVA test was applied, as summarized in Table 5.

Table 5. Three Way ANOVA analysis results for the impact of variables on the tool as a whole

\begin{tabular}{cccccc}
\hline Variance Source & Sum of squares & df & Mean of squares & F. value & Sig \\
\hline Gender & 0.03 & 1 & 0.03 & 0.62 & 0.55 \\
Qualification & 0.27 & 1 & 0.27 & 3.58 & 0.04 \\
Teaching experience & 0.32 & 1 & 0.32 & 3.88 & 0.02 \\
Error & 4.61 & 58 & 0.04 & & \\
Total & 5.33 & 61 & & \\
\hline
\end{tabular}

Table 5 shows that:

The variable of gender value was of (0.62) whereas the statistical significance was at $(0.55)$ which is not significant at $(\alpha \leq 0.05)$. This indicates that there is no effect of the variable of gender on the degree of having secondary teachers of mathematics at schools of Al-Mafraq governorate for the evaluation competences in their view with a total male mean of (3.40) and (3.39)for total female. The evidence supports the conclusion that the results of this study were consistent with the results of the study of (Rababah, 2016) and (Abaid, 2008). The researcher attributed that female and male teachers receive the same training and guidance from the educational specialists regarding the evaluation competences during practicing their teaching work.

Besides, scientific qualification variable value was of (3.58) and the statistical significance was at (0.04), which is the value of statistical function at the level of significance $(\alpha \leq 0.05)$, indicating the effect of the qualified variable on the degree of having evaluation competences was medium, in favor of the scientific qualification (higher than the bachelor's degree) with mean of (3.84).

The results of this study were consistent with the results of the study of (AlSuggaf, 2008), (AlThubaiti, 2005), (Qoqazeh, 2003), and (AlZahrani, 2002), while it is inconsistent with the result of the study of each (Alrababah, 2016) and (Omari, 2010). The researcher attributed this to that teachers who have higher qualifications than the bachelor have had often studied educational materials related to measurement and evaluation of education and how to apply in the field of work related to the teaching process, while the verification of all teachers who have a higher qualification of the bachelor in participants of the sample, that their educational qualifications ranged between the educational diploma after the bachelor and master in the curriculum and teaching and not strictly related to their specialization through the study tool and personal information.

Furthermore, value of $(\mathrm{F})$ of the variable of experience in domain of teaching was at (3.88) and statistical significance was at (0.02), the value of statistical function at the level of significance $(\alpha \leq 0.05)$ indicating the impact of the variable experience on domain of teaching mathematics of teachers for the secondary stage at schools of Mafraq governorate for the evaluation competences ranked high in favor of years of experience (more than five). So, results of this study were consistent with the study of (Al Rababah, 2016), (AlOmari, 2010), (AlSuaggaf, 2008), (AlThubaiti, 2005), (Qoqazeh, 2003), and (AlZahrani, 2002). The researcher attributed that to teachers of mathematics with more than five years of experience have developed themselves professionally and educationally as opposed to new teachers who lack experience in this field. In addition, the teaching experience provides the teacher with various teaching methods and strategies, during the working years and 
under the supervision of school administration and appropriate guidance by educational supervisors. To determine the significance of these differences, a multivariate triangulation analysis test was used to determine the effect of scientific qualification, experience and specialization on each of the two domains of the list of evaluation competences as shown in Table 6.

Table 6 shows the results of analysis of the three way ANOVA, analysis of multivariate to detect the impact of variables on each domain.

\begin{tabular}{ccccccc}
\hline \multirow{2}{*}{ Variance source } & Independent variables & $\begin{array}{c}\text { Sum of } \\
\text { squares }\end{array}$ & df & $\begin{array}{c}\text { Mean of } \\
\text { squares }\end{array}$ & F. value & Sig. \\
\hline \multirow{2}{*}{ Gender } & Personal evaluation competences & 0.10 & 1 & 0.10 & 0.16 & 0.85 \\
& Cognitive evaluation competences & 0.08 & 1 & 0.08 & 2.14 & 0.98 \\
qualification & Personal evaluation competences & 0.12 & 1 & 0.12 & 2.26 & 0.14 \\
& Cognitive evaluation competences & 0.36 & 1 & 0.36 & 3.28 & 0.03 \\
\multirow{2}{*}{ Teaching experience } & Personal evaluation competences & 0.42 & 1 & 0.42 & 4.22 & 0.04 \\
& Cognitive evaluation competences & 0.14 & 1 & 0.14 & 1.54 & 0.24 \\
& Personal evaluation competences & 7.32 & 60 & 0.03 & & \\
& Cognitive evaluation competences & 5.22 & 60 & 0.02 & & \\
& Personal evaluation competences & 7.88 & 61 & & &
\end{tabular}

Table 6 points out that there are statistically significant differences $(\alpha \leq 0.05)$ in the degree of having teacher of mathematics the evaluation competences due to the qualification of the teacher of mathematics in the domain of cognitive competences. The value of $(F)$ and its statistical significance at (0.03) and for those higher than the bachelor as seen above. The researcher considers that the cognitive competences gained by the teacher through his study of the educational subjects studied after the bachelor, which provided him with a lot of cognitive competences evaluation, also Table 6 shows there are differences of statistical significance at $(\alpha \leq 0.05)$ in which teachers of mathematics having the evaluation competences. The researcher attributed to the experience of the mathematics teacher in domain of personal evaluation. Where the value of (F) in domain of personal competences evaluation was of (4.22), while statistical significance was at (0.04) for those with experience more than five years and as shown in Table 4.

In the context of explanation in the table above, the researcher attributed that result to the fact that the greater the teacher's experience, the greater the degree of his personal skills. Since the teacher is more aware, engaged and interacting with his entire school environment through his observations, discussions and continuous training with all colleagues of his school environment for all aspects of his personality. From all aspects related to teaching competences and unlike the modern teacher who lacks mostly aforementioned.

\section{Recommendations}

Based on the results of the study, the researcher recommends the Ministry of Education to hold workshops and training courses for teachers of mathematics at the secondary stage regarding the importance of having the personal and cognitive skills of the teachers of mathematics at the secondary stage for their development professionally, and help them know the importance of the teacher. To address this need, it was necessary to involve the students in selecting the evaluation tools and criteria and agreeing with them and building collection tests, good testing and utilization of the results of it and its use to address the weaknesses and enrich the strengths, apply them to a high degree linked to the system of accountability and strengthening, because of the great importance of improving the performance of our students.

\section{References}

Abaid, S. A. (2008). Effectiveness of on-service training courses in developing the competences of teachers of mathematics in building achievement tests for the basic stage in Jordan (Unpublished master dissertation). Amman Arab University for Graduate Studies, Amman, Jordan.

Al Rababah, I. H. (2016). Educational competences required for teachers of Arabic language for non-Arabic speakers and the extent of their practice. Dirasat Journal, Humanities and Social Sciences, 43(Supplement 4), University of Jordan, Amman-Jordan.

AlAdwan, Z., \& Al-Hawamdeh, M. (2015). Design of Teaching between Theory and Practice (pp. 189-192.). Dar Al-Masirah for Publishing and Distribution, Amman: Jordan. 
Almezian, S., \& Gharrab, H. (2005). The basic competences of kindergarten teachers from the point of view of the directors of Riyadh. A research presented to the second educational conference "Palestinian children between the challenges of reality and the aspirations of the future", held in the Faculty of Education at the Islamic University in the period from 11-23 / 22-2005, Gaza.

AlOmari, M. B. B. Q. (2010). Competences for teaching the course of mathematics developed and the degree of availability of teachers (Unpublished master dissertation). Um AlQura University, Mecca, Saudi Arabia.

AlRashidi, K. M. (2007). The Degree of Having of Teachers of Mathematics in Teaching Skills and Their Relation to the Achievement of their Students at the Primary Stage in Kuwait (Unpublished master dissertation). Amman Arab University for Graduate Studies, Amman - Jordan.

AlSaqrat, K. A. (2006). Evaluation of the performance of female students / female teachers class in the light of the educational competences necessary for teaching and the construction of a proposed training program and measurement of effectiveness at the University of Mutah - Jordan (Unpublished Dissertation). Faculty of Education - University of Damascus, Syria.

AlSuggaf, A. O. (2008). Educational competences required for the teacher of mathematics and the degree of practice at the secondary stage in Abyan governorate (Unpublished master dissertation). University of Aden, Yemen.

AlTanawi, E. M. (2013). Effective Teaching (I 3, pp. 225-230). Dar Al Masirah for Publishing and Distribution, Amman: Jordan.

AlThubaiti, D. A. (2005). The availability and practice of educational competences in the preparation, correction and analysis of the test of secondary school teachers of mathematics in Taif Educational City (Unpublished master dissertation). Um Al Qura University, Mecca.

AlZahrani, M. M. (2002). The reality of having of teachers of mathematics in the primary stage of knowledge competences to prepare achievement tests (Unpublished master dissertation). Um AlQura University, Mecca, Saudi Arabia.

AlZahrani, M. M. (2009). The reality of the performance of secondary school teachers of mathematics in light of contemporary professional standards and the relationship of this to the achievement of their students (Unpublished doctoral dissertation). Um AlQura University, Mecca Al-Mukarramah, KSA. http://www.pdffactory.com

Ghareeb, A. K. (2006). Educational Manhal: An Encyclopaedia Dictionary of Pedagogic, Didiacetic and Pedagogical Concepts and Concepts - Part I A-H. World of Education Publications (p. 162). Al-Najah Al-Jadida Press, Casablanca.

Ministry of Education. (2006). National Standards for Professional Teacher Development. National Teacher Education Standards Conference, Amman, Jordan.

Mustafa, N. N. (2010). Evaluation Strategies in Education (pp. 83-85). Amman Home Publishers \& Distributors.

Odeh, A. S. (2010). Measurement and Evaluation in the Teaching Process. I 4, Dar Al Amal for Publishing and Distribution: Irbid - Jordan.

Othman, M. (2011). Educational Evaluation Methods (pp. 20-21). Dar Osama for Publishing and Distribution, Amman: Jordan.

Popham, J. (2005). The teaching process: What teachers need to know (pp. 17-20). Translated by Muayad Fawzi, Dar Al Kutab, Gaza: Palestine.

Qoqazeh, S. (2003). Availability and Practice of Educational Technology Competences of Secondary School Teachers in Jerash Governorate (Unpublished master dissertation). A L-AlBayt University, Jordan.

Ta'imah, R. A. (2006). Teacher, Skills, Preparation, Training. I 2, Dar Al Fikr Al Arabi, Cairo - Egypt.

Varma, C. (2007). Improving Quality of Elementary Education by Monitoring Professional Competences of Teachers for Inclusive Education. ERIC-Education Resources Information Center (ED494892).

\section{Copyrights}

Copyright for this article is retained by the author(s), with first publication rights granted to the journal.

This is an open-access article distributed under the terms and conditions of the Creative Commons Attribution license (http://creativecommons.org/licenses/by/4.0/). 